\title{
Amperometric and spectrophotometric determination of carbaryl in natural waters and commercial formulations
}

Dionísia C. Portela · Isabel M. F. Pereira · Paula Paíga Cristina

Delerue-Matos · M. Carmo V. F. Vaz

\begin{abstract}
The work presented describes the development and evaluation of two flow-injection analysis (FIA) systems for the automated determination of carbaryl in spiked natural waters and commercial formulations. Samples are injected directly into the system where they are subjected to alkaline hydrolysis thus forming 1naphthol. This prod- uct is readily oxidised at a glassy carbon electrode. The electrochemical behaviour of 1naphthol allows the devel- opment of an FIA system with an amperometric detector in which 1-naphthol determination, and thus measurement of carbaryl concentration, can be performed. Linear re- sponse over the range 1.0 ? $10^{-7}$ to 1.0 ? $10^{-5} \mathrm{~mol} \mathrm{~L}^{-1}$, with a sampling rate of 80 samples $\mathrm{h}^{-1}$, was recorded. The detec- tion limit was 1.0 ? $10^{-8} \mathrm{~mol} \mathrm{~L}^{-1}$. Another FIA manifold was constructed but this used a colorimetric detector. The method- ology was based on the coupling of 1-naphthol with phenyl- hydrazine hydrochloride to produce a red complex which has maximum absorbance at $495 \mathrm{~nm}$. The response was linear from 1.0 ? $10^{-5}$ to 1.5 ? $10^{-3} \mathrm{~mol}$ $\mathrm{L}^{-1}$ with a detection limit of 1.0 ? $10^{-6} \mathrm{~mol} \mathrm{~L}^{-1}$. Samplethroughput was about 60 samples $\mathrm{h}^{-1}$. Validation of the results provided by the two FIA methodologies was performed by comparing them with results from a standard HPLC-UV technique. The relative deviation was $<5 \%$. Recovery trials were also carried out and the values obtained ranged from 97.0 to $102.0 \%$ for both methods. The repeatability (RSD, \%) of 12 consecutive injections of one sample was $0.8 \%$ and $1.6 \%$ for the amperometric and colorimetric systems, re- spectively.
\end{abstract}

Keywords Amperometry - Spectrophotometry · Carbaryl-Pesticides - Flow-injection analysis
Introduction

The carbamates belong to a group of pesticides that has attained great popularity in recent years due to their broad biological activity [1]. They are used as insecticides, miti- cides, fungicides and molluscicides [1]. Because of the wide range of uses in the treatment of seeds, soils, or crops [1], the methyl carbamates constitute one of the most im- portant classes in this group and of these, carbaryl (1-naph- thyl $\mathrm{N}$-methyl carbamate) has been one of the most used because it has low oral and skin toxicity in spite of its great insecticide capacity [2].

Most of the analytical methods employed for the quan- titation of carbaryl have been based on chromatographic techniques. Classical gas chromatography has been shown to be generally unsatisfactory due to the thermal instabil- ity of carbaryl, requiring either a chemical derivation step (use of different reagents) or the employment of short columns, specially treated columns or short capillaries [1]. Thus many authors have preferred to make use of liquid chromatography (generally reversed-phase) linked to var- ious detectors, e.g. UV [3], diode-array [4, 5], florescence

$[5,6]$, or electrochemical [7], although some of these methods also require pre-treatment steps to form detectable derivatives. Thin-layer chromatography has occasionally been employed [8].

Other methods for estimation of carbaryl in various matrices are found in the literature. These include: spec- trophotometric techniques using UV/vis $[9,10,11,12]$,

infrared spectrometry [13], and electrochemistry [1, 2]. All these are founded on the conversion of carbaryl to 1naph- thol by means of alkaline hydrolysis. The spectrophoto- metric methods using UV/vis detection mention several chromogenic reagents that form coloured complexes with

1-naphthol in order to achieve an appropriate selectivity and sensitivity of the spectrophotometric measurements. The ease with which 1-naphthol is oxidised allows satis- factory detection using electrochemistry based on a differ- ential pulse voltammetric method [1]. The coulometric ox- idation product of carbaryl at a platinum electrode (1,4naphthoquinine) can also be determined electrochemically. 

This is performed either directly by adsorptive stripping voltammetry or indirectly by differential pulse polarography after reduction of the oxidation product $(1,4-$ naphtho- quinine) at a dropping mercury electrode [2].

The increasingly widespread use of pesticides, frequently unregulated, linked to the growing concern for environ- mental problems has made the determination of the con- centrations of these compounds progressively more fre- quent and rigorous. To respond to these demands control laboratories have had to introduce automated analyses that reduce substantially the time required for analysis and allow the development of high-throughput capability.

Flow-injection analysis (FIA) can provide this requirement while presenting as an additional advantage the pos- sibility of employing common laboratory equipment and reducing drastically reagent consumption as compared with traditional batch procedures. FIA coupled to a spectro- photometric detector has already been used by Boaven- tura et al. [14] and Ricardo et al. [15]. In the first article 1-naphthol was reacted with $p$ aminophenol to yield a blue complex with maximum absorbance at $596 \mathrm{~nm}$. The methodology developed by Ricardo et al. [15], is based on the preconcentration of carbaryl into a polyether type polyurethane foam followed by on-line elution with di- chloromethane and measurement of absorbance at $280 \mathrm{~nm}$. An amperometric flow-injection biosensor device for determination of carbaryl by means of 4-aminophenol quan- tification was also proposed. This xenobiotic agent was here responsible for the inhibition of the acetyl cholin- esterase activity toward the substrate 4aminophenylacetate. The enzyme was immobilised at the surface of a glassy carbon electrode thus recording the decrease of the amount of 4-aminophenol [16].

The present work reports on the development of two FIA systems which enable determinations of carbaryl in two different ranges of concentration without prior treat- ment of samples. Alkaline hydrolysis of carbaryl to 1naph- thol is carried out inside both systems and the latter com- pound is quantitated. The first system makes use of the ease of electrochemical oxidation of 1naphthol at a glassy carbon electrode and has an amperometric detector. In the other system 1-naphthol reacts with phenylhydrazine hy- drochloride to give a red complex with absorbance mea- surement at $495 \mathrm{~nm}$.

Experimental

\section{Reagents and solutions}

Carbaryl (Pestanal grade, 99.9\%) was purchased from Riedel-deHaën and used without further purification. solutions of 1-naphthol were prepared by diluting the stock solu- tion with water.

Acetate buffer solutions of $\mathrm{pH}$ from 4.0 to 5.9 were used as support electrolyte and were prepared by mixing different volumes of acetic acid and sodium acetate solutions, both $2.0 \mathrm{~mol} \mathrm{~L}^{-1}$, until the desired $\mathrm{pH}$ was reached. Subsequent dilution was performed to furnish solutions with a final ionic strength of $0.2 \mathrm{~mol} \mathrm{~L}^{-}$ 1.

In the comparison method (chromatographic determination) solvents were of HPLC grade. Before use they were filtered and any dissolved air was removed by bubbling helium through the so- lution.

\section{Standard and sample preparation}

Stock solutions of carbaryl $\left(1.0\right.$ 回 $\left.10^{-2} \mathrm{~mol} \mathrm{~L}^{-1}\right)$ were prepared with an exact weight of the pure pesticide, dissolved in the least quan- tity of $N, N$ dimethylformamide (DMF) and diluting to $10.00 \mathrm{~mL}$ with water. The resulting solution was kept in the dark at $+4{ }^{\circ} \mathrm{C}$. The standard solutions used for the optimisation studies and plot- ting calibration curves were prepared by dilution of these stock so- lutions with water. These solutions were stable for at least one week if kept in the dark at $+4{ }^{\circ} \mathrm{C}$ when not in use.

Natural water samples were collected from various locations in Porto (rivers and lakes) in dark glass bottles. The samples were spiked with carbaryl and directly analysed by the different method- ologies using the calibration curve method.

In the commercial product (Permutex, Permutadora) the pro- portion of carbaryl present is $50 \%(w / w)$; therefore the sample stock solution $\left(3.0\right.$ ? $\left.10^{-4} \mathrm{~mol} \mathrm{~L}^{-1}\right)$ was prepared by accurately weighing $0.0060 \mathrm{~g}$ of the commercial sample and adding a few drops of DMF until complete dilution. Water was then added and the total volume was adjusted to 50.00 $\mathrm{mL}$. The sample stock solution was diluted with water in order to obtain a concentration within the calibration curve range. In the spectrophotometric system the formulations were passed through a 0.45 ]m membrane filter before introduc-tion into the system, to avoid turbidity or particulate contamination that might affect the analytical signal.

\section{Apparatus}

HPLC readings under batch conditions were made by means of aSykam A 1210 liquid chromatograph equipped with a model 3200 UV detector tuned to $222 \mathrm{~nm}$. Separation of sample components was accomplished on a Supercosil LC-18 column $(250 \mathrm{~mm}$ ? $4.6 \mathrm{~mm}, 5$ ? $\mathrm{m}$ particle size) from Macherey-Nagel, Germany.

The FIA systems comprised a Gilson Minipuls 3 peristaltic pump, fitted with PVC tubing $(1.0 \mathrm{~mm}$ i.d.) and a four-way Rheodyne type 5020 injection valve. PTFE tubing (Omnifit, Teflon, $0.8 \mathrm{~mm}$ i.d.) and Gilson end-fittings and connectors were used to connect all the components of the manifold. Other auxiliary devices, such as Perspex Y-shaped confluences constructed as previously de-scribed [17], were also used.

The output signals were recorded on a Kipp and Zonen BD 112

recorder.

All other chemicalswere Merck pro analysis grade and all solutions were prepared us- ing purified water (conductivity $<0.1$ ? $\mathrm{S} \mathrm{cm}^{-1}$ ) obtained from a Barn- stead Epure 4 system.

The phenylhydrazine hydrochloride solution $10.3 \%$ $w / v)$ was prepared from the corresponding solid and dissolved in water. This solution was prepared daily and 
kept in a closed container away from light in order to avoid oxidation.

Stock solutions of 1 -naphthol $\left(1.0\right.$ ? $\left.10^{-2} \mathrm{~mol} \mathrm{~L}^{-1}\right)$ were prepared by careful weighing of the solid, dissolution in the least quantity of ethanol, and diluting to volume with water. More dilute working
The spectrophotometric detector was a Jenway 6300 single- beam unit comprising a 100-? through cell and an optical path length of $10 \mathrm{~mm}$.

Amperometric detection was performed by use of a 641 VA Metrohm detector linked to a 656 Metrohm wall-jet containing a three-electrode system - a glassy carbon working electrode (Metrohm $6.0805 .010)(d=3.0 \mathrm{~mm})$, an $\mathrm{Ag} / \mathrm{AgCl} / \mathrm{KCl} 3.00 \mathrm{~mol} \mathrm{~L}^{-1}$ reference electrode (Metrohm 6.07027.000), and a gold counter-electrode (Metrohm 6.530.320).

When necessary the working electrode was mechanically cleaned by polishing its surface using the specified polishing kit (Metrohm 6.2802.010), first with ?-Al2O3 (0.3 ?m) until a shining surface was obtained and afterwards only with water.

The $\mathrm{pH}$ of buffer solutions was determined with a Crison 2002 ? pH meter with a Sentek 71728 combined glass electrode. 


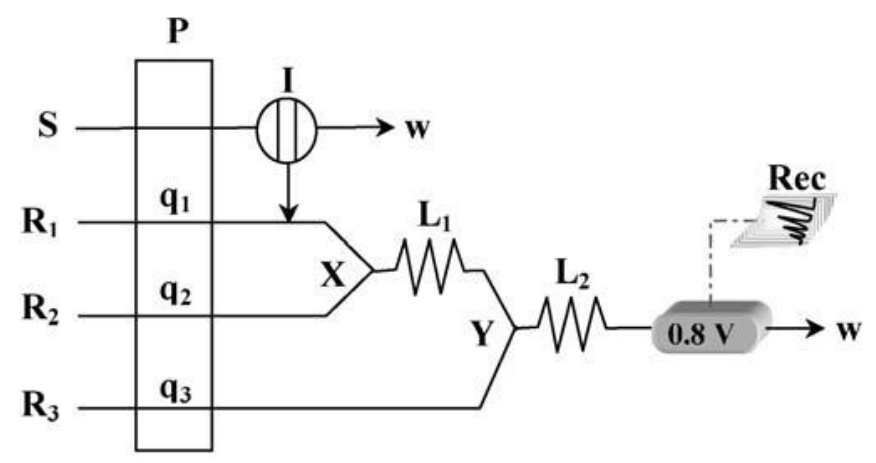

Fig. 1 Flow-injection system with amperometric detection: $P$, peri- staltic pump; $S$, sample; $I$, injection volume (215 ?L); $R 1$, carrierstream (water); $R 2$, sodium hydroxide solution $(0.02 \mathrm{~mol} \mathrm{~L}-1) ; R 3$, acetate buffer solution $(\mathrm{pH}=5.0) ; X, Y$, confluence points; $L n$, reac-tors $(L 1=30 \mathrm{~cm}, L 2=250 \mathrm{~cm}) ; q 1=q 2=1.0 \mathrm{~mL} \mathrm{~min}^{-1}, q 3=2.0 \mathrm{~mL}$ min $^{-1} ; D E T$, detector; Rec, recorder; $W$, waste

\section{Comparison method}

Results from amperometric and spectrophotometric analysis were compared with those obtained using an independent method em- ployed by Riedel-de Haën for quality control of pro analisis grade reagent [18]. HPLC was performed at room temperature with a mixture of water $(60 \%)$ and acetonitrile $(40 \%)$ as mobile phase at a flow rate of $1.35 \mathrm{~mL} \mathrm{~min}^{-1}$. Calibration was performed by injec- tion of 20 ? $\mathrm{L}$ of carbaryl standard solutions, with concentrations of 1.0 ? $10^{-6}$ to 8.0 ? $10^{-6} \mathrm{~mol} \mathrm{~L}^{-1}$ and 5.0 ? $10^{-5}$ to 5.0 ? $10^{-4} \mathrm{~mol} \mathrm{~L}^{-1}$ for the amperometric and spectrophotometric systems, respectively.

Flow-injection configuration

\section{Amperometric detector}

The manifold used for the determination of carbaryl with ampero- metric detection has two confluence points and

is depicted in Fig. 1. A sample (I) was introduced in an ultra-pure water carrier stream (R1) without previous

treatment and the sample plug was then con- veyed to the confluence $X$ where $\mathrm{NaOH}$ solution (R2) is added to

the flow. Alkaline hydrolysis occurs in the coiled tube reactor ( $L 1)$; the bolus travels to the confluence $Y$ where it merges with buffer acetate solution (R3) and in reactor $\mathrm{L} 2$ the ionic strength and $\mathrm{pH}$ adjustment are made as is required by the detector.

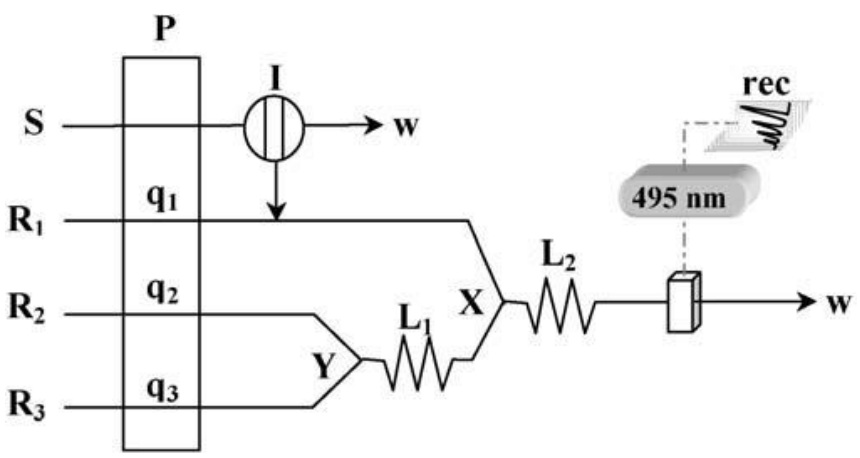

Fig. 2 Flow-injection system with spectrophotometric detection: $P$, peristaltic pump; $S$, sample; $I$, injection volume (215 ? L); $R 1$, car- rier stream (water); $R 2$, sodium hydroxide solution $\left(2.0 \mathrm{~mol} \mathrm{~L}^{-1}\right) ; R 3$, phenylhydrazine solution $0.3 \% ; X, Y$, confluence points; $L_{\eta}$, re- actors $(L 1=30 \mathrm{~cm}, L 2=700 \mathrm{~cm}) ; q 2=q 3=0.7 \mathrm{~mL} \mathrm{~min}^{-1}, q 1=1.4 \mathrm{~mL}$ $\min ^{-1}$; Rec, recorder; $W$, waste 
A schematic representation of the FIA manifold with spectropho- tometric detector is shown in Fig. 2.

Each sample aliquot was injected in a water carrier stream (R1) and merged at the $X$ confluence with a solution of phenylhydrazine hydrochloride (R3) and $\mathrm{NaOH}$ (R2) prepared in reactor (L1). Alka- line hydrolysis of carbaryl occurred in the coiled tube reactor (L2) forming 1-naphthol which in turn reacts with the phenylhydrazine hydrochloride to give a red complex with absorbance measurement at $495 \mathrm{~nm}$.

Results and discussion

Optimisation of the FIA systems

FIA manifolds were designed and then optimized to ob- tain the lowest detection limit possible while maximising sample throughput, sensitivity, and precision without sam- ple pre-treatment. All necessary modifications to the sam- ples were effected within the FIA system. After prelimi- nary experiments to establish the manifold designs and parameters, a univariant optimization procedure was ap- plied and this will be separately described.

\section{Amperometric system}

Because carbaryl is not electroactive and the hydrolysis product (1-naphthol) is readily oxidised at the glassy car- bon electrode, optimization was started by investigating the effect of $\mathrm{pH}$ of the support electrolyte and of the work- ing electrode potential in a simpler, double-channel sys- tem (Fig. 3) in which a standard solution of 1-naphthol (concentration 1.0? $10^{-5} \mathrm{~mol} \mathrm{~L}^{-}$ $\left.{ }^{1}\right)$ was inserted into a flow of water $\left(R_{1}\right)$. At confluence $X$ the acetate buffer solution was added $\left(R_{2}\right)$ to change the $\mathrm{pH}$ and ionic strength in re- actor $\mathrm{L}_{1}$ before arriving at the detector. Based on the pre- vious results of the voltammetric study [1] the potential was fixed at $+0.80 \mathrm{~V}$ and the $\mathrm{pH}$ was varied from 4.0 to 5.9 . Within this $\mathrm{pH}$ range, the best results - higher absolute re- sponse and better reproducibility-were obtained at $\mathrm{pH} 5.0$.

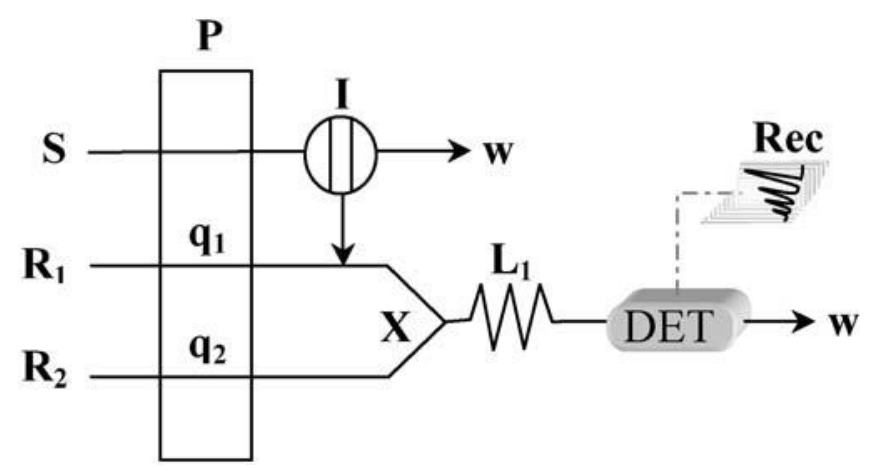

Fig. 3 Flow-injection system used for optimization: $P$, peristaltic pump; $S$, sample; $I$, injection volume (215 目L); $R 1$, carrier stream (water); $R 2$, acetate buffer solution; $X$, confluence point; $L 1$, reac- tor; $q 1, q 2$, 
With acetate buffer solution of pH 5.0 as the support electrolyte, the oxidation potential of the working electrode was varied from 0.60 to $1.30 \mathrm{~V}$ vs. $\mathrm{Ag} / \mathrm{AgCl}$, finding an optimum at $0.80-1.0 \mathrm{~V}$. Up to $0.80 \mathrm{~V}$, increasing the potential led to a significant increase in peak height. Between 0.80 and $1.0 \mathrm{~V}$ the signal was fairly constant, above

$1.0 \mathrm{~V}$ the analytical response decreased significantly and reproducibility suffered accordingly. This behaviour of the detection system indicated that the range 0.80 to 1.0

$\mathrm{V}$ would lead to the highest possible sensitivity. To reduce possible interference from compounds other thancarbaryl present in real samples, the potential of $0.80 \mathrm{~V}$ was cho- sen. The length of rector $L_{1}$ was fixed at $30 \mathrm{~cm}$ to give the best compromise between sensitivity and reproducibility. Following the optimization of support electrode $\mathrm{pH}$ and the oxidation potential, the next step was to study the effect of changing the concentration of sodium hydroxide used in the alkaline

hydrolysis. This required the con-struction of an FIA system with two confluences (Fig. 1) in which the standard solutions of carbaryl (concentra-tions 1.0? $10^{-7}$ to 8.0 ? $10^{-6} \mathrm{~mol} \mathrm{~L}^{-1}$ ) were inserted into the ultra-pure water stream and carried to confluence $X$ where the sodium hydroxide stream was added in order for the alkaline hydrolysis to occur in the reactor (L1).

The re-sulting 1-naphthol-containing flow then encountered the acetate buffer at confluence $\mathrm{Y}$ and $\mathrm{pH}$ and ionic strength adjustment proceeded in reactor $L_{2}$ before finally reaching the detector. The sodium hydroxide concentration is a fun-damental parameter for the optimization of this FIA sys- tem and therefore a wide range of strengths was tested $\left(0.005-0.06 \mathrm{~mol} \mathrm{~L}^{-}\right.$ $1)$. Up to $0.02 \mathrm{~mol} \mathrm{~L}^{-1}$ the analytical signal increased with concentration, thus this level was chosen for subsequent

runs. The degree of hydrolysis was studied for each concentration of sodium hydroxide tested by comparing the analytical signals obtained from stan- dard solutions of 1-naphthol or carbaryl with the same concentrations. Again, the highest efficiency was noted to be at the chosen concentration of sodium

\section{$1.2 \mathrm{molL}^{-1}$.}

hydroxide -

1-Naphthol was formed in reactor $L_{1}$ and so five lengths $(33-500 \mathrm{~cm}$ ) were tested. The length of $250 \mathrm{~cm}$ was cho- sen, since smaller ones decreased the sensitivity and re- producibility due, presumably, to insufficient mixing of the sample with the $\mathrm{NaOH}$ solution and with longer ones the sensitivity and sampling rate decreased due to the dis- persion effect. Both reactors (L1 and L2) were coiled to improve radial mixing and minimise the dispersion of the sample plug [19].

With the purpose of selecting the most suitable injection volume, several values were tested in the range of 160 to 420 ? $\mathrm{L}$ and it was found that the best sensitivity and reproducibility was achieved with 215 ? L. Therefore this was the volume chosen.

The optimum flow rate at the detector was found to be $4 \mathrm{~mL} \mathrm{~min}^{-1}$; although no higher flow rates were tried, be- cause they would have exceeded the maximum flow rate allowed in the wall-jet cell [20].

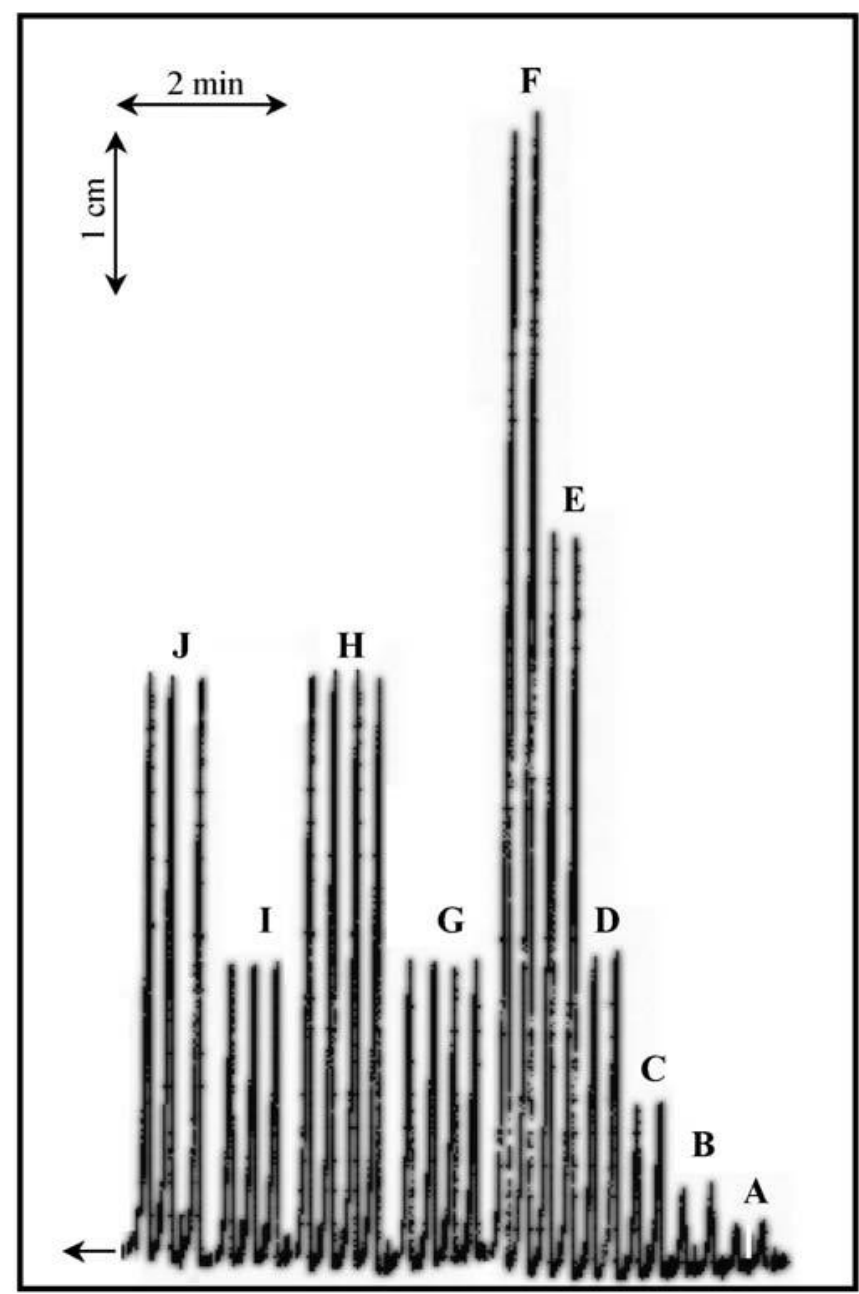

Fig. 4 Flow injection signals obtained with the amperometric sys- tem corresponding to injection of a set of standards of carbaryl and samples with recoveries. $A$. 2.0? $10^{-7} \mathrm{~mol} \mathrm{~L}^{-1}$; B. 5.0?10-7 $\mathrm{mol} \mathrm{L}^{-1}$; $C$, 1.0 ? $10^{-6} \mathrm{~mol} \mathrm{~L}^{-1} ; D$. 2.0?10-6 $\mathrm{mol} \mathrm{L}^{-1} ; E$, 5.0? $10^{-6} \mathrm{~mol} \mathrm{~L}^{-1}$;

$F$, 8.0 $10^{-6} \mathrm{~mol}^{-1} ; G$, sample 2 (in Table 1 ); $H$, recovery trial of sample 2 ; $I$, sample 1 (in Table 1 ); $J$, recovery trial of sample 1

\section{Spectrophotometric system}

The 1-naphthol-phenylhydrazine reaction occurs at strongly alkaline $\mathrm{pH}$ [8]. To select the appropriate $\mathrm{pH}$ for formation of the coloured complex, phenylhydrazine solutions of concentrations between 0.25 and $1.0 \%$ were prepared in sodium hydroxide solutions of 0.5 to $2.5 \mathrm{~mol}$ $\mathrm{L}^{-1}$ concen- tration (Fig. 2, reactor $\mathrm{L}_{1}$ ). The colour intensity of the complex was determined by measuring the absorbance of 1.0 ? $10^{-5}, 1.0$ ? $10^{-4}$, and 1.0 ? $10^{-3} \mathrm{~mol}$ $\mathrm{L}^{-1}$ standard solutions of carbaryl. The maximum absorbance was achieved with a phenylhydrazine concentration of $0.3 \%$ in $2.0 \mathrm{~mol} \mathrm{~L}^{-1}$ sodium hydroxide solution.

Several characteristics of the FIA system - flow rate, injection volume and reaction coil length - were also optimized.

The length of reactor $\mathrm{L}_{1}$ was tested from 10 to 50 $\mathrm{cm}$; the value $30 \mathrm{~cm}$ was chosen as it allowed the best results in terms of sensitivity and reproducibility. It 
seems that 
Table 1 Determination of car- baryl by use of FIA and HPLC

Values are means and standard deviations from five and three determinations by FIA and HPLC, respectively aspiked water samples

b Commercial formulation

mixing of both solutions occurs very quickly and that increasing the length of this reactor results in a dilution effect.

With the first reactor set to $30 \mathrm{~cm}$ the length of the sec- ond (L2) was varied from 400 to $750 \mathrm{~cm}$. The sensitivity increased with increasing coil length until 700 cm, after which sensitivity started decreasing, presumably as a re-sult of the dispersion effect.

Under the conditions already selected the injection vol- ume was varied from 100 to 500 ?L. As expected, in- creasing the injection volume led to an increase in sensi- tivity, especially for low injection volumes. Having regard for the compromise between sensitivity, reagent consump- tion, and sampling rate, the injection volume of 215 ? $\mathrm{L}$ was selected.

Flow rates before confluence $Y$ were equal to avoid using more concentrated and therefore less stable solutions, which is particularly important for phenylhydrazine. Vari- ous flow rates were tried between 2.0 and $4.0 \mathrm{~mL} \mathrm{~min}^{-1}$ and $2.8 \mathrm{~mL} \mathrm{~min}^{-1}$ was selected, because lower values re- duced the sampling rate and at higher values the sensitiv- ity was significantly affected.

\section{Determination of carbaryl in samples}

With the conditions as specified above, linear calibration plots were obtained over the ranges 1.0 ? $10^{-7}-1.0$ ? $10^{-5}$ $\mathrm{mol} \mathrm{L}^{-1}\left(y=864703 x+0.1932 R^{2}=0.9996\right)$ and 1.0 ? $10^{-5}$ 1.5 国 $10^{-3} \mathrm{~mol} \mathrm{~L}^{-1}$

$\left(y=136.97 x+0.0005 R^{2}=0.9992\right)$ for determination of carbaryl with the amperometric (Fig. 4) and spectrophotometric systems respectively. The suitability of the developed FIA systems for estimation of carbaryl was assessed by analysing four samples (three samples of spiked water, and one commercial preparation) and the mean values from five determinations, with standard deviations, are shown in Table 1 . Validation of the results was confirmed by com- parison with the values obtained from HPLC determinations and the relative errors were always $<5 \%$. Recovery trials ranged from $97 \%$ to $102 \%$ confirming the accuracy of the developed systems. The detection limits of the methods calculated under the optimized conditions and according to IUPAC recommendations [21] were 5.0? $10^{-8} \mathrm{~mol} \mathrm{~L}^{-1}$ and 5.0 ? $10^{-6} \mathrm{~mol} \mathrm{~L}^{-1}$ of pesticide for the amperometric and spectrophotometric systems respectively. The precision of the FIA methods was estimated by calculating the relative standard deviation from 12 consecutive injections of one sample. The relative standard deviations were lower than $2.0 \%$ for both systems. 
Conclusions

The automated FIA systems developed constitute good al- ternatives to conventional methods. The results are highly comparable, the sampling rates are higher, and there is considerable saving of reagents. The advantages are both environmental and economic.

It should also be noted that the equipment used is eas- ily accessible in any control laboratory and that with the two systems proposed it is possible to quantify carbaryl without pretreatment of the samples over the range 1.0 ? $10^{-7} \mathrm{~mol} \mathrm{~L}^{-1}$ to 1.5 ? $10^{-3} \mathrm{~mol} \mathrm{~L}^{-1}$. The two systems are com- plementary: in the amperometric detection system concen- trations of carbaryl higher than 1.0 ? $10^{-5} \mathrm{~mol} \mathrm{~L}^{-1}$ cannot be measured due to signal irreproducibility caused by adsorp- tion problems on the surface of the working electrode; with the spectrophotometric system higher concentrations are easily measured.

Acknowledgements The authors acknowledge Fundação para a Ciência e Tecnologia and Feder for financial support (POCTI/ 35287/AGR/1999).

References

1. Guiberteau A, Díaz TG, Salinas F, Ortiz JM (1995) Anal Chim Acta 307:219-226

2. Pérez-López JA, Zapardiek A, Bermejo E, Arauzo E, Hernán- dez L (1994) Fresenius J Anal Chem 350:620-625

3. Gil-Agusti M, Alvarez-Rodriguez L, MonferrerPons L, Bose D, Durgbanshi A, Esteve-Romero J (2002) Anal Lett 35:1721-1734

4. Toscano IAS, Ribeiro ML, Santelli SE, Guardia M (2000) Quim Nova 23:466-471

5. Hidalgo C, Sancho JV, Roig-Navarro A, Hernandez F (1998) Chromatographia 47:596-600

6. Abad A, Moreno MJ, Pelegri R, Martinez MI, Saez A, Gamon M, Montoya A (1999) J Chromatogr A 833:3-12

7. Diaz TG, Guiberteau A, Salinas F, Ortiz JM (1996) J Liq Chro- matogr Related Technol 19:2681-2690

8. Patil VB, Shingare MS (1993) J Chromatogr A 653:181-183

9. Tunceli A, Bag H, Turker AR ( 2001) Fresenius J Anal Chem 371:1134-1138

10. Demirbas A (2000) Environ Technol 21:351-356

11. Demirbas A (1998) Sci Total Environ 220:235-241

12. Alvarez Rodriguez L, Monferrer-Pons L, Esteve Romero JS, Garcia Alvarez CMC, Ramis Ramos G (1997) Analyst 122: 459-463

13. Daghbouche Y, Garrigues S, Guardia M (1995) Anal Chim Acta 314:203-212

14. Reis BF, Morales-Rubio A, Guardia M (1999) Anal Chim Acta 392:265-272 
15. Cassela RJ, Garrigues S, Santelli RE, Guardia M (2000) Ta- lanta 52:717-725

16. La Rosa C, Pariente $F$, Hernández L, Lorenzo E (1995) Anal Chim Acta 308:129-136

17. Alegret S, Alonso J, Bartroli J, Machado AASC, Lima JLFC, Paulis JM (1987) Quim Anal 6:278-292

18. Riedel-de Haën (1999) Certificate of analysis, carbaryl
19. Ruzicka J, Hansen EH (1988) Flow-injection analysis, 2nd edn. Wiley, New York

20. Metrohm (1984) Electrochemical detection in HPLC. Metrohm AG, CH-9100, Herisau

21. Miller JC, Miller JN (1993) Statistics for analytical chemistry, 3rd edn. Ellis Horwood, New York 